\section{Birlesik Dünya Arastırma New Trends and Issues BD-CENTER Proceedings on Humanities and Innovasyon ve Yayıneilık Merkezi \\ Social Sciences}

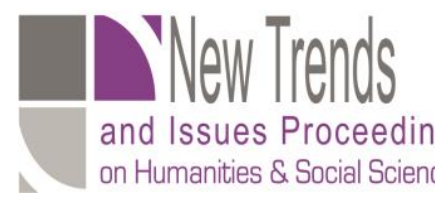

Volume 7, Issue 3, (2020) 215-223

www.prosoc.eu

Selected Paper of 9th Cyprus International Conference on Educational Research (CYICER-2020) 18-20 June 2020, Bahçeşehir Cyprus University Nicosia / TRNC (ONLINE CONFERENCE)

\title{
The development of strength under endurance conditions and agility in international soccertennis players
}

Corina Tifrea*, National University of Physical Education and Sports, 140 Constantin Noica Street, 060057 Bucharest, Romania

Anamaria Gherghel, National University of Physical Education and Sports, 140 Constantin Noica Street, 060057 Bucharest, Romania https://orcid.org/0000-0002-5769-3464

Raluca Costache, National University of Physical Education and Sports, 140 Constantin Noica Street, 060057 Bucharest, Romania

\section{Suggested Citation:}

Tifrea, C., Gherghel, A. \& Costache (2020).The development of strength under endurance conditions and agility in international soccer tennis players. New Trends and Issues Proceedings on Humanities and Social Sciences. 7(3), pp 215-223. Available from: www.prosoc.eu

Received from July 12, 2020; revised from August 12, 2020; accepted from November 15, 2020.

Selection and peer review under responsibility of Prof. Dr. Huseyin Uzunboylu, Higher Education Planning, Supervision, Accreditation and Coordination Board, Cyprus.

${ }^{\circ} 2020$ Birlesik Dunya Yenilik Arastirmave YayincilikMerkezi. All rights reserved.

\begin{abstract}
Soccer tennis is a sport which appeared in 1922, and in 1940 the first official regulations appeared. It is a sport practiced both individually and as a team, here finding the single, double and triple events, and double and triple mixed events.

Purpose: Our study highlights the aspects of the training programme for worldwide players in soccer tennis from Romania. Method and instruments for data collection: This study highlights in particular the development of the mobility quality of the force under endurance and agility conditions with the help of the Opto Jump device. It is a complex sport wherein all the muscle groups are involved, technical-tactical aspects are involved and all mobility qualities are involved: speed (reaction, execution, movement, in force and endurance); force (force-speed and force-resistance); resistance (specific and anaerobic); flexibility and mobility; and coordinating capacity.

Conclusion and recommendation: The specialised literature at national and international levels does not abound in scientific publications about football tennis.
\end{abstract}

Keywords: Performance, soccer, strength, mobility, agility, training, evaluation.

\footnotetext{
* ADDRESS FOR CORRESPONDENCE: Raluca Costache, National University of Physical Education and Sports, 140 Constantin Noica Street, 060057 Bucharest, Romania E-mail address: rally kyn@yahoo.com
} 


\section{Introduction}

The history of the sport, known as football tennis, can be placed exactly in 1992, when members of the Slavia Prague football club in the Czech Republic started practicing as a leisure activity a sport that they called football over the rope (the net was a horizontal rope, which was replaced with a net).

In 1940, the first officially written and recognised rules appeared. In the same year, the first official football tennis competition took place, and between 1953 and 1961 the first championship (league) was organised and held. On February 7, 1987, the International Football Tennis Federation was officially registered as the International Football Tennis Association (IFTA). In 1991, the first European Championship was organised by the IFTA. Three years later, the IFTA organised the first World Cup, which took place in Brazil, and the first World Championship, which took place in Slovakia. All the above-mentioned tournaments, made by the IFTA with its appearance, led to the incorporation and organisation of the European Champions Cup at the club level (the first edition took place in the Czech Republic in 1996).

At the national level, football tennis can be said to have been practiced since the 1970s, but under a different name. The first competitions organised, and of special importance, date back to 1982-1989.

Since 1992 and until now, the Romanian national team has participated in all championships and cups (world and European) with outstanding results. It should be mentioned that between 1993 and 1994, the first national championship and the first Romanian cup were held under the aegis of the FRFT-CAJ.

It is a sport practiced both individually and as a team, here finding the single, double and triple events, and double and triple mixed events, which is practiced by both men and women. It is a complex sport wherein all the muscle groups are involved, technical-tactical aspects are involved and all mobility qualities are involved: speed (reaction, execution, movement, in force and endurance); force (force-speed and force-resistance); resistance (specific and anaerobic); flexibility and mobility; and coordinating capacity.

The specialised literature at national and international levels does not abound in scientific publications about football tennis. It is worth mentioning that Romania, at the competitive level (world championships, European championships and world cups) has remarkable results in all the categories in which it participates.

Our study highlights the aspects of the training programme for worldwide players in soccer tennis, from Romania, highlighting in particular the development of the mobility quality of the force under endurance and agility conditions with the help of the Opto Jump device.

\section{Methods}

The research methods used in this paper are the following:

$\checkmark$ The pedagogical observation method

$\checkmark$ The pedagogical experiment method

$\checkmark$ The statistical-mathematical method

$\checkmark$ The inquiry method

\subsection{Study hypothesis}

The use of operational modules will contribute to the development of strength in endurance, specific agility and performance in women's soccer tennis.

The scientific research lasted for a period of 10 months, with 10 members of the National Football Tennis team, within the Izvorani Olympic Centre, at the National University of Physical Education and 
Sport. The training of the players consisted of three preparatory periods/40 training sessions/stage; three pre-competitive periods/20 practice sessions/stage and three competitive periods/10 training sessions/stage. As an example regarding the training programme for the development of strength in endurance and agility development, we will present two training models.

\section{Content}

\subsection{Periodisation of training}

At this level of performance, physical training must be very well performed and include the following:

- development of general physical training;

- development of motor skills;

- morpho-functional training;

- anaerobic and mixed resistance for short or medium duration efforts;

- specific endurance obtained through repeated exercises in both training and games;

- general strength through muscle development and dynamic strength;

- mobility and suppleness through mobility and stretching exercises;

- speed of reaction, execution and movement.

Training objectives:

Physical training through:

- development of aerobic/anaerobic/mixed effort capacity

- development of speed in speed and endurance in speed

Technical training:

- perfecting the takeovers

- improving the attack and technical blows (short, erased and elbowed)

Tactical training:

- improving aggressive defence (in a triangle or waterfall)

- improving the defence with the man left blocked

Psychological training:

- self-overcoming capacity

Some of the programmes to develop strength in endurance and agility of the performance of soccer tennis players are as follows, where in progress was achieved with the Opto Jump test battery:

1. Jump for 60 seconds.

Walk around with your eyes closed for 30 seconds.

Opto Jump is known as an innovative system of analysis and measurement and represents a new philosophy, whose role is to evaluate and optimise performance in the world of competitive sports: it is created to develop a specific and customised training programme for athletes, based exclusively on data and precise goals.

With the help of the Opto Jump it is possible:

- to assess the athlete's performance and physical condition;

- to rapidly identify any muscle deficiency and measure tolerance of different workloads;

- to develop a personalised form and diversification based on test results;

- to periodically verify training results; 
- to create a database of athletes in order to compare them or to compare the results of a certain athlete in different periods of time;

- to objectively determine training results.

The data that can be measured and calculated in real time are the following:

- Contact time

- Flight time

- Height

- Steps (cadence and rhythm)

- Specific power

Training programme on speed and agility development (Tables 1 and 2)

2. Strength under endurance conditions

Training 1

a. F1: with knees bent at 90 degrees - knee flexion, then alternate lifting in front and above of the lower limbs with sandbags (1 kg per member), climbing and descending off the gym bench for $1^{\prime}\left(4 \times 30 \times 1^{\prime} \times 30 " p \times 80 \%\right)$. Time: $80 \%$; dosage: $1-3 x$; passive break: 1 minute; and line formation on a row at $1 \mathrm{~m}$ of net.

b. F2: lying down, lifting the lower limbs with weights ( $1 \mathrm{~kg}$ per member) at 180 degrees and returning, vertical jumps on both legs for $1^{\prime}\left(4 \times 30 \times 1^{\prime} \times 30^{\prime \prime}\right.$ px80\%). Time: $80 \%$; dosage: $1-3 x$; passive break: 1 minute; line formation on a row at $1 \mathrm{~m}$ of net.

c. F3: lying face down, support on the palms, the lower limbs alternately flex and extend, sprint on $50 \mathrm{~m}(4 \times 30 \times 50 \mathrm{~m} \times 30 " \mathrm{px} 80 \%)$. Time: $80 \%$; dosage: $1-3 \mathrm{x}$; passive break: 1 minute; line formation on a row.

d. F4: lying dorsally with the hands on the neck and lower limbs bent at 90 degrees, lifting the

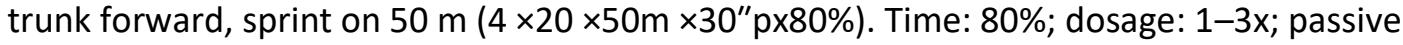
break: 1 minute; line formation on a row at $1 \mathrm{~m}$ of net.

e. F5: in pairs $(2 \times 2)$. the executing one is at the back with the soles on the ground, and with the knees bent at 90 degrees; the partner at $2 \mathrm{~m}$ from it, throws the ball at the head, lifting the trunk towards before and as high as possible of the ball, knee flexion for $1^{\prime}\left(4 \times 15 \times 1^{\prime} \times 1^{\prime}\right.$ px80\%).Time80\%; dosage 1-3x; passive break: 1 minute; line formation on two lines.

f. F6: the performer is positioned on the left side line of the playing field and at $2 \mathrm{~m}$ from the net, front/back lunge with knee bending at 90 degrees, self-pass and diagonal attack with the soccer tennis ball $(4 \times 10 \times 20 \times 30 " p \times 80 \%)$. Time: $80 \%$; dosage: $1-3 x$; passive break 1 minute; line formation on a row at $1 \mathrm{~m}$ of net.

g. F7: the performer is positioned on the left side line of the playing field and at $2 \mathrm{~m}$ from the net, knee flexion with bending at 90 degrees, self-pass and along the line attack (Figure 1) with the soccer tennis ball $(4 \times 10 \times 20 \times 30 " p \times 80 \%)$. Time: $80 \%$; dosage: $1-3 x$; passive break: 1 minute; working formation: in column one to $1 \mathrm{~m}$ of net.

h. F8: standing, alternating push-ups with jumping from one foot to the other on the bosu ball, return, sprint on $10 \mathrm{~m}(4 \times 20 \times 10 \times 30 " p \times 70 \%)$. Volume: $90 \%$; intensity: $70 \%$; dosage: $1-3 x$; passive break: 30 seconds; work formation: line in a row.

i. F9: running on the gym bench, squat with a jump at the bosu ball, sprint on $10 \mathrm{~m}(4 \times 3 \times 10$ $\times 310 \mathrm{~m})$. Volume: $90 \%$; intensity: $70 \%$; dosage: $1-3 x$; passive break: 30 seconds; work formation: in a column in twos.

j. F10: sitting, squat with jump on the bosu ball, hold for 3 seconds, turn, sprint on $10 \mathrm{~m}(4 \times 10$ $\times 10 \times 30 "$ px70\%). Volume: $90 \%$; intensity: $70 \%$; dosage: $1-3 x$; passive break: 30 seconds; work formation: line in a row. 
k. F11: rope jumps with sandbags (1 kg on each leg), lying face down, palm support, with vertical jumps ( $4 \times 1^{\prime} \times 15 \times 30 "$ px70\%). Volume: $90 \%$; intensity: $70 \%$; dosage: $1-3 \times$; passive break: 30 seconds; work formation: line in a row.

I. F12:the performer is positioned on the left side line of the field of play and $2 \mathrm{~m}$ away from the net, jumping with his knees to his chest, self-pass and along the line attack (Figure 1 ) with the soccer tennis ball $(4 \times 10 \times 20 \times 30 "$ px70\%). Volume: $90 \%$; intensity: $70 \%$; dosage: $1-3 x$; passive break: 1 minute; work formation: line in a row at 1 maway from the net.

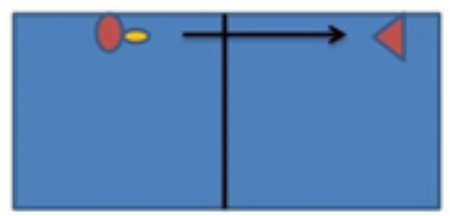

Figure 1. Side attack along the line

m.F13: in pairs, the player is positioned at the centre line of the field of play (Figure 2) and at $2 \mathrm{~m}$ away from the net, jumping with his knees up over an obstacle, passes from the partner and along the line attack from the centre area with the soccer tennis ball (waterfall defence|) $(4 \times 10 \times 20 \times 30 " \mathrm{px} 70 \%)$. Volume: 90\%; intensity: 70\%; dosage: 1-3x; passive break: 1 minute; work formation: line in a row at 1 $\mathrm{m}$ of net.

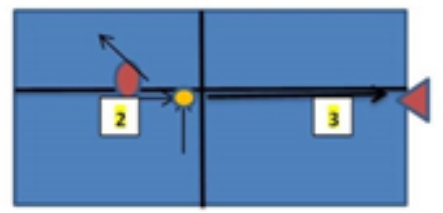

3. Agility

Figure2. Side attack along the line of the middle area

Training 1

a. CC1: standing, straight trunk, arms forward and perfectly outstretched, knees bent at 90 degrees and with the tip of the lower limbs pointing inward, lifting on the tips and maintaining the initial position without placing the heel on the ground, running with the back on $10 \mathrm{~m} \mathrm{(4}$ $\times 30^{\prime \prime} \times 10 \times 30^{\prime \prime}$ px85\%). Time: $85 \%$; dosage: $1-3 x$; passive pause: 30 seconds; line formation on a row.

b. CC1: standing, right trunk, arms forward and perfectly outstretched, knees bent at 90 degrees and with the tip of the lower limbs facing outward, lifting on the tips and maintaining the initial position without placing the heel on the ground, running with the back on $10 \mathrm{~m}\left(4 \times 30^{\prime \prime} \times 10\right.$ $\times 30 "$ px85\%). Time: $85 \%$; dosage: $1-3 x$; passive pause: 30 seconds; line formation on a row.

c. CC3: standing, alternating jumps from one foot to another with the knee rising to 90 degrees and stopping on each leg, holding 5 seconds, turning, $10-\mathrm{m}$ sprint ( $4 \times 10 \times 10 \times 30 " \mathrm{px} 85 \%)$. Time: $85 \%$; dosage: $1-3 x$; passive pause: 30 seconds; line formation on a row.

d. CC4: standing, the ball at the players, taking the ball with the flat side, in place and throwing the ball over the head, return and taking, top attack. It is executed without letting the ball fall to the ground ( $\left.4 \times 5 \times 10 \times 30^{\prime \prime} \times 85 \%\right)$. Time: $85 \%$; dosage: $1-3 \times$; passive pause: 30 seconds; line formation on a row.

e. CC5: standing, in pairs (three players each), two balls at the end players, placed in the line and $3 \mathrm{~m}$ from the net, the centre player takes the ball from the partner, passes it back, returns and takes the ball from the partner at the whistle, the player from the centre attacks diagonally $(4 \times 7 \times 10 \times 30 " x 85 \%)$. Time: $85 \%$; dosage: $1-3 x$; passive pause: 30 seconds; work formation: in column three each. 
We briefly present the minimum and maximum values from the initial testing to the final testing in Tables 1 and 2 and Graphic 1.

\section{Results}

Table 1. Initial Testing 60 seconds jumps

\begin{tabular}{lcccccc}
\hline \multicolumn{1}{c}{ Name and surname } & $\begin{array}{c}\text { Contact } \\
\text { time(seconds) }\end{array}$ & $\begin{array}{c}\text { Flight time } \\
\text { (seconds) }\end{array}$ & $\begin{array}{c}\text { Height of the } \\
\text { jump (cm) }\end{array}$ & $\begin{array}{c}\text { Force of the } \\
\text { jump(w/kg) }\end{array}$ & $\begin{array}{c}\text { Steps } \\
\text { (step/second) }\end{array}$ & $\begin{array}{c}\text { RSI } \\
\text { (m/second) }\end{array}$ \\
\hline 1. G. A. Minimum & 0.142 & 0.306 & 11.5 & 25.01 & 1.60 & 0.84 \\
Maximum & 0.194 & 0.468 & 26.8 & 45.44 & 1.88 & 1.75 \\
Coefficient of variability & $5.6 \%$ & $6.0 \%$ & $11.8 \%$ & $12.0 \%$ & $3.5 \%$ & $14.3 \%$ \\
2. R. A. M. Minimum & 0.198 & 0.254 & 7.9 & 12.17 & 0.88 & 0.31 \\
Maximum & 0.262 & 0.916 & 102.9 & 113.72 & 2.02 & 4.68 \\
Coefficient of variability & $6.8 \%$ & $20.1 \%$ & $65.7 \%$ & $48.7 \%$ & $6.6 \%$ & $66.7 \%$ \\
3. C. F. Minimum & 0.174 & 0.262 & 8.4 & 19.28 & 1.68 & 0.60 \\
Maximum & 0.222 & 0.412 & 20.8 & 32.33 & 2.00 & 1.14 \\
Coefficient of variability & $4.6 \%$ & $5.8 \%$ & $11.3 \%$ & $9.6 \%$ & $3.9 \%$ & $12.2 \%$ \\
4. L. M. Minimum & 0.182 & 0.246 & 7.4 & 11.98 & 0.39 & 0.31 \\
Maximum & 0.254 & 2.378 & 693.2 & 704.57 & 2.11 & 33.01 \\
Coefficient of variability & $6.6 \%$ & $78.2 \%$ & $274.6 \%$ & $224.7 \%$ & $18.0 \%$ & $271.4 \%$ \\
5. V. B. Minimum & 0.212 & 0.274 & 9.2 & 13.05 & 1.66 & 0.32 \\
Maximum & 0.292 & 0.366 & 16.4 & 23.14 & 1.85 & 0.74 \\
Coefficient of variability & $6.0 \%$ & $6.1 \%$ & $12.3 \%$ & $12.6 \%$ & $2.3 \%$ & $18.4 \%$ \\
6. P. P. Minimum & 0.168 & 0.216 & 5.7 & 9.32 & 0.46 & 0.21 \\
Maximum & 0.274 & 2.016 & 498.2 & 630.09 & 2.12 & 29.65 \\
Coefficient of variability & $12.3 \%$ & $57.9 \%$ & $257.7 \%$ & $222.5 \%$ & $11.6 \%$ & $288.3 \%$ \\
7. R. Adr. Minimum & 0.184 & 0.162 & 3.2 & 5.98 & 0.99 & 0.11 \\
Maximum & 0.303 & 0.812 & 80.8 & 98.78 & 2.23 & 4.04 \\
Coefficient of variability & $12.0 \%$ & $25.5 \%$ & $82.8 \%$ & $64.5 \%$ & $7.0 \%$ & $94.9 \%$ \\
8. B. B. Minimum & 0.212 & 0.190 & 4.4 & 8.15 & 1.82 & 0.17 \\
Maximum & 0.278 & 0.334 & 13.7 & 20.45 & 2.15 & 0.63 \\
Coefficient of variability & $7.3 \%$ & $12.0 \%$ & $22.9 \%$ & $20.8 \%$ & $3.5 \%$ & $29.4 \%$ \\
9. N. A. Minimum & 0.040 & 0.046 & 0.3 & 1.23 & 0.12 & 0.01 \\
Maximum & 0.402 & 8.100 & $8,042.6$ & $4,302.52$ & 7.14 & 209.44 \\
Coefficient of variability & $13.2 \%$ & $359.1 \%$ & $996.4 \%$ & $907.4 \%$ & $26.4 \%$ & $977.4 \%$ \\
10. D. B. Minimum & 0.222 & 0.156 & 3.0 & 5.66 & 1.94 & 0.10 \\
Maximum & 0.300 & 0.242 & 7.2 & 11.99 & 2.50 & 0.31 \\
Coefficient of variability & $7.2 \%$ & $9.1 \%$ & $18.8 \%$ & $14.7 \%$ & $4.1 \%$ & $21.1 \%$ \\
\hline
\end{tabular}

Table 2. Final testing 60 seconds jumps

\begin{tabular}{lcccccc}
\hline $\begin{array}{c}\text { Name and } \\
\text { surname }\end{array}$ & $\begin{array}{c}\text { Contact } \\
\text { time(seconds) }\end{array}$ & $\begin{array}{c}\text { Flight time } \\
\text { (seconds) }\end{array}$ & $\begin{array}{c}\text { Height of the } \\
\text { jump }(\mathbf{c m})\end{array}$ & $\begin{array}{c}\text { Force of the } \\
\text { jump(w/kg) }\end{array}$ & $\begin{array}{c}\text { Steps } \\
\text { (step/second) }\end{array}$ & $\begin{array}{c}\text { RSI } \\
\text { (m/second) }\end{array}$ \\
\hline 1. G. A. Minimum & 0.140 & 0.354 & 15.4 & 26.06 & 1.45 & 0.88 \\
Maximum & 0.190 & 0.536 & 35.2 & 62.66 & 1.91 & 2.52 \\
Divergence & 0.004 & -0.068 & -8.4 & -17.22 & -0.03 & -0.77 \\
C. V. & $6.3 \%$ & $8.1 \%$ & $16.2 \%$ & $16.3 \%$ & $5.4 \%$ & $19.1 \%$ \\
2. R. A. M. & 0.191 & 0.297 & 10.8 & 16.09 & 1.55 & 0.45 \\
Minimum & & & & & & \\
Maximum & 0.260 & 0.431 & 22.8 & 33.74 & 1.90 & 1.19 \\
Divergence & -0.069 & -0.134 & -12 & -17.65 & -0.35 & -0.74
\end{tabular}


C.V.

3. C. F. Minimum

Maximum

Divergence

C. V.

4. L.M. Minimum

Maximum

Divergence

C. V.

5. V. B. Minimum

Maximum

Divergence

C.V.

6.P.P. Minimum

Maximum

Divergence

C. V.

7. R. Adr. Minimum

Maximum

Divergence

C. V.

8. B. B. Minimum

Maximum

Divergence

C. V.

9. N. A. Minimum

Maximum

Divergence

C. V.

10. D. B. Minimum

Maximum

Divergence

C. V.

\begin{tabular}{cc}
$5.9 \%$ & $10.5 \%$ \\
0.172 & 0.270 \\
0.226 & 0.372 \\
-0.054 & -0.102 \\
$5.9 \%$ & $7.5 \%$ \\
0.202 & 0.332 \\
0.248 & 0.497 \\
-0.046 & -0.165 \\
$4.9 \%$ & $10.8 \%$ \\
0.218 & 0.126 \\
0.338 & 0.290 \\
-0.123 & -0.014 \\
$9.2 \%$ & $13.6 \%$ \\
0.189 & 0.208 \\
0.268 & 0.415 \\
-0.079 & -0.207 \\
$7.0 \%$ & $13.6 \%$ \\
0.191 & 0.126 \\
0.286 & 0.350 \\
-0.095 & -0.224 \\
$8.6 \%$ & $16.5 \%$ \\
0.222 & 0.156 \\
0.322 & 0.242 \\
-0.102 & -0.032 \\
$7.2 \%$ & $9.1 \%$ \\
0.250 & 0.074 \\
7.490 & 0.282 \\
-0.16 & -0.208 \\
$181.7 \%$ & $19.5 \%$ \\
0.158 & 0.298 \\
0.232 & 0.506 \\
-0.088 & -0.104 \\
$5.0 \%$ & $6.2 \%$ \\
\hline
\end{tabular}

$21.0 \%$

8.9

17.0

$-8.1$

$14.5 \%$

13.5

30.3

$-16.8$

$21.7 \%$

1.9

10.3

$-0.5$

$26.7 \%$

5.3

21.1

$-15.8$

$26.4 \%$

1.9

15.0

$-13.1$

$32.4 \%$

3.0

7.2

$-1.9$

$18.8 \%$

0.7

9.7

$-9$

$36.4 \%$

10.9

31.4

$-5.6$

$11.4 \%$
$19.7 \%$

14.89

28.29

$-13.4$

$14.4 \%$

19.02

39.96

$-20.94$

$20.0 \%$

4.65

15.61

$-1.61$

$21.0 \%$

8.88

30.23

$-21.35$

$24.7 \%$

4.36

23.60

$-19.24$

$29.6 \%$

5.66

11.99

$-2.79$

$14.7 \%$

2.05

13.97

$-11.92$

$30.3 \%$

26.50

44.25

$-7.4$

$10.0 \%$
$5.2 \%$

1.72

2.02

$-0.3$

$3.2 \%$

1.39

1.77

$-0.38$

$5.7 \%$

1.87

2.55

$-0.75$

$5.3 \%$

1.60

2.10

$-0.5$

$6.0 \%$

1.84

2.43

$-0.59$

$5.2 \%$

1.99

2.50

$-0.6$

$4,1 \%$

0.13

2.04

$-1.91$

$16.2 \%$

1.41

1.68

$-0.32$

$3.3 \%$

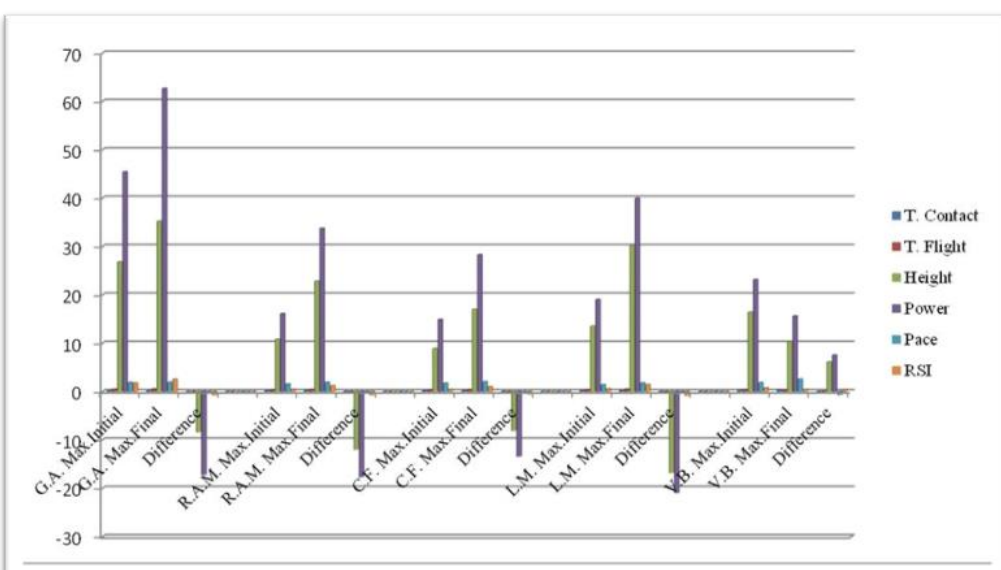

$25.7 \%$

0.42

0.99

$-0.57$

$18.8 \%$

0.56

1.43

$-0.87$

$24.7 \%$

0.08

0.44

0.06

$29.2 \%$

0.20

1.04

$-0.84$

$32.1 \%$

0.07

0.77

$-0.7$

$41.9 \%$

0.10

0.31

$-0.08$

$21.1 \%$

0.00

0.37

$-0.37$

$53.8 \%$

0.88

1.68

$-0.25$

$12.5 \%$

Graphic1. Initial / final evaluations of the values obtained with Opto Jump 


\section{Conclusion and recommendations}

Following the research carried out and the results obtained with the Opto Jump test battery and the training models used in the research, regarding the development of strength in endurance and the development of agility, we observed an improvement in these motor qualities, resulting from the fact that the training models were effective.

It was found that the value of the maximum average from the final test to the initial one, regarding the vertical jump for 60 seconds, had improved the difference of the average of the whole lot: contact time: 0.751 seconds; flight time: 0.669 seconds; jump height: $793 \mathrm{~cm}$; bounce power: $415 \mathrm{w} / \mathrm{kg}$; number of steps: $0.247 / \mathrm{second}$; and RSI: $20.34 \mathrm{~m} / \mathrm{second}$, resulting in the development of the strength in resistance regime with the help of the training models implemented during the research period.

The difference for the coefficient of variability of the average of the maximum values from the initial test to the final test is given by the following data: contact time: 0.160 ; flight time: $0.46 \%$; jump height: $1.52 \%$; jump power: $1.33 \%$; steps: $0.027 \%$; CSR: $1.51 \%$, which led to increased homogeneity and strength under endurance conditions.

The difference for the standard deviation of the average of the maximum values from the initial test to the final test was contact time: $0.02 \%$; flight time: 0.29 ; jump height: $88.7 \%$; jump power: $50 \%$; steps: $0.04 \%$; and RSI: $2.28 \%$, which resulted in increased homogeneity and strength under endurance conditions. It was found that the average of the maximum value from the final test compared to the initial one was improved, with respect to walking in place with eyes closed for 30 seconds, the difference of the average of the whole lot being: 0.65 seconds; flight time: 0.76 seconds; steps $/ \mathrm{m}$ : 19.01 steps/m; steps/cycle: 0.16 cycle/second; cycle: 2.40 seconds; jumping point SD: $9.26 \mathrm{~cm}$; F/S jumping point: $0.97 \mathrm{~cm}$; SD: $1.21 \mathrm{~cm}$; deviate $F / S: 10.31 \mathrm{~cm}$; and area used: $31.61 \mathrm{~cm}^{2}$, resulting in the development of strength under endurance conditions with the help of training models implemented during the research period.

The difference for the average of the coefficient of variability of the maximum value from the initial test to the final test was contact time: 5.64 seconds; flight time: 0.39 seconds; steps $/ \mathrm{m}: 0.24$ steps $/ \mathrm{m}$; steps/cycle: 0.04 cycle/second; cycle: 0.18 seconds; jumping point SD: $1.08 \mathrm{~cm}$; F/S jumping point: $0.56 \mathrm{~cm}$; deviation S/D: $70.5 \mathrm{~cm}$; deviated $\mathrm{F} / \mathrm{S}: 0.44 \mathrm{~cm}$; and area used: $0.11 \mathrm{~cm}^{2}$, the one that increased the homogeneity and the force under endurance conditions.

The difference regarding the average of the standard deviation of the maximum value from the initial test to the final test was contact time: 0.002 seconds; flight time: 0.0105 seconds; steps $/ \mathrm{m}: 0.06$ steps/m; steps/cycle: 0.00 cycle/second; cycle: 0.001 second; jumping point SD: $0.02 \mathrm{~cm}$; F/S jump point: $1.67 \mathrm{~cm}$; SD: $0.12 \mathrm{~cm}$; deviate $\mathrm{F} / \mathrm{S}$ : $0.001 \mathrm{~cm}$; area used: $5.67 \mathrm{~cm}^{2}$, which led to increased homogeneity and strength under endurance conditions.

In order to obtain notable sporting results in important competitions, it is necessary that both general and specific trainings be based on a well-monitored and controlled training programme and the methods and means by which they are developed and maintained must be at high parameters in order to achieve the desired performance. Given all the arguments presented in this paper, we can say that all technical and tactical aspects, both individual and collective, are important aspects in the process of sports training, more precisely they can lead to a positive feedback in terms of efficiency of the means used within the trainings as well as the efficiency of the technical-tactical aspects of the football tennis athletes.

Following the results obtained with the Opto Jump device in both the initial and final tests, it can be stated that the training models used through the football tennis game were effective, observing from the statistical interpretations that there were quality improvements involved, more exactly the strength and coordination ability. 
In conclusion, we can say that football tennis contributes to the education and development of motoric skills as well as to physical and technical-tactical training; their permanent practice can lead to self-overcoming and high sports performance.

Following the application of questionnaires in more developed countries where women's soccer tennis is practiced, questions related to the number of trainings/weekly cycle allotted for the development of moving qualities, and it was concluded that in Romania there are a greater number of trainings for the development of strength under endurance conditions.

\section{References}

Bompa, T. O. (2003). Performantain jocurile sportive - Teoria simetodologiaantrenamentului. Bucuresti, Romania: Scoala Nationalade Antrenori, Editura Ponto. (Performance in sports games-training theory and methodology, National School of Coaches, Ed. Ponto, Bucharest).

Didier, R. \& Pascal, P. (2013). La bible de la preparation physique. Barcelona, Spain: Editura Amphora.

Garcia, J. L. A. (1994). Balonmano: Metodologia y alto rendimiento. Barcelona, Spain: EdituraPaidotribo.

Millet, G. L'endurance. Paris, France: Edition Revue EPS.

Wong, P. I., Chouachi, A., Chamari, K., Della A. \& Wisloff, U. (2010). Effect of preseason concurrent muscular strenght and hight intensity interval training in professional soccer players. Journal of Strenght and Conditioning Research, 24(3), 653-660. 